\title{
Interpretative Phenomenological Analysis: A means of exploring aspiration and resilience amongst Widening Participation students
}

\author{
Lizzie Gauntlett, Bournemouth University \\ Ed Bickle, Bournemouth University \\ Gail Thomas, Bournemouth University \\ Bethan Collins, University of Liverpool \\ Vanessa Heaslip, Bournemouth University \\ Sue Eccles, Bournemouth University \\ Email: egauntlett@bournemouth.ac.uk
}

DOI: http://doi.org/10.5456/WPLL.19.2.xxx

\begin{abstract}
As the Office for Fair Access and the Higher Education Funding Council for England priorities now extend across widened access to success, both the aspirations of young people from widening participation (WP) backgrounds and their existing or developing resilience as students are of concern to Higher Education institutions. In this paper, these positive psychology concepts of aspiration and resilience are used in two different studies each seeking to move away from the prevalent discourse of deficit. This paper thus offers the joint perspective of two researchers exploring the phenomena of a) aspiration in students from low participation neighbourhoods and b) resilience in students from lowincome backgrounds. Interpretative Phenomenological Analysis (IPA) is utilised by both to offer a credible, insightful research approach which may enable educators, researchers and policy-makers to appreciate the nature and significance of WP students' experiences in a previously unseen way, thus enabling effective interventions and methods of support. Through in-depth exploration of the cognitions and emotions of young people from WP backgrounds, the researchers discuss how listening to individual stories can provide rich data that may enhance future support for students. Important methodological challenges and the implications of applying IPA to both studies are debated; including use of language
\end{abstract}


to convey meaning, the role of researcher reflexivity and the difficulties in achieving a truly interpretative account of the phenomenon. Whilst often a challenging methodology, IPA can provide rich, contextualised accounts which contribute to the limited extant qualitative literature on WP student aspiration and resilience.

Key words Widening Participation; Qualitative Research; Interpretative Phenomenological Analysis; Researcher Experience; Aspiration; Resilience

\section{Introduction}

The need to widen participation within UK Higher Education Institutions (HEIs) has become a major social policy over the last twenty years. This is likely to remain the case for some time, with the 2016 Higher Education (HE) White Paper (Success as a Knowledge Economy: Teaching Excellence, Social Mobility \& Student Choice) having reaffirmed the fact that it 'will put providers' performance in achieving positive outcomes for disadvantaged students at the heart of the TEF' (DBIS 2016, p.49), whilst also requiring HE institutions to have an approved Access and Participation Agreement (or a short statement demonstrating their commitment to widening participation (WP)) should they wish to apply for the Teaching Excellence Framework.

The 2016 White Paper also re-emphasised the lifecycle approach to WP to ensure institutions focus support on WP students to help them achieve their potential as well as focusing on access (DBIS 2016). This was in opposition to earlier definitions of WP which were concerned with focusing solely on admission to HE (HEFCE 2006). This approach has placed a greater emphasis on institutions to establish evidence-based practice in relation to WP and for understanding the lived experiences of WP students across the student lifecycle.

Funding for both $\mathrm{PhD}$ studentships outlined in this paper come from Bournemouth University's (BU) Access Agreement (a document agreed by the Office for Fair Access (OFFA), that sets out the universities fee limits and access measures it will put in place ${ }^{1}$ ), underpinning their institutional obligation to develop empirical evidence around maximising access to and success within HE of learners from underrepresented groups. 
The studentships are supported by the Fair Access Research team and are designed to enable BU to understand what is helpful and unhelpful in their approach to WP outreach and what promotes the success of underrepresented groups while in the university. The aim is not only to contribute to the evidence base, but also to enhance policy and practice to support access and student success. Both studies aim to do this by enhancing our understanding of the lived experience of WP students, whilst adopting a positive psychology model, as opposed to a deficit-focused one which places the 'blame' for lower levels of HE participation and success on the learner. In this sense, both studies seek to answer the question: By adopting a phenomenological perspective and by listening to individual stories, how can future interventions and support for WP students in accessing and succeeding within HE be enhanced?

The first of these studies is concerned with access to HE. As part of the drive to widen participation, The Higher Education Funding Council for England (HEFCE) announced in March 2016, that from academic year 2016-17 a new national collaborative outreach programme would be rolled out, specifically focusing activity in areas of the country where HE participation is particularly low. This has re-emphasised the need for HEIs to provide effective, targeted outreach programmes to raise the aspirations of young people living in a 'Low Participation Neighbourhood' (LPN), in other words, areas that have lower than average HE progression rates for young people ${ }^{2}$ to aspire to HE (as well as under-represented groups such as lower socio-economic groups and care leavers). This is despite LPN being seen as a measure of relative rather than absolute disadvantage (UUK 2016), with Harrison and McCaig (2015) suggesting that more families defined as disadvantaged actually live outside of LPN's than inside.

The focus on aspiration appears to be based on the belief that aspirations are a key precursor to future attainment and life outcomes (Social Exclusion Task Force 2008), and are highly correlated with background (Harris 2010). This can be set within a wider movement from a policy of expectation, where the onus is on the state to ensure citizens received equal outcomes (Sellar et al. 2011) to the development of an aspirational state, with the aspirational citizen 'eager to take on greater responsibility for themselves and the well-being of their communities' (Raco 2009, p.436).

However, there is evidence to suggest that the aspirations of young people from WP backgrounds are not as low as implied in policy. Archer et al. (2014), for example, found that the aspirations of young people were generally comparable across all social-class backgrounds. Similarly, in their 
study of young people in disadvantaged settings Kintrea et al. (2015) found high levels of aspiration, whilst Turok et al. (2009) also challenge the idea that there is a poverty of aspiration amongst young disadvantaged people. This has led to a number of studies suggesting that rather than low aspirations, the real issue is what Appadurai (2004) describes as the capacity to aspire, in other words, a lack of opportunity and conditions for aspirations to be realised (Baker et al. 2014). It is therefore this capacity to aspire (rather than aspiration per se) that needs to be strengthened.

Although aspiration-raising is a key concept within WP policy and practice, there is a lack of research within the field that seeks to gain a fuller understanding of not only the aspirations of a key WP target group but how these aspirations are shaped by everyday lived experience.

The second of these studies is concerned with the experience of resilience in undergraduate students from low-income backgrounds. In UK HE, research is now needed to understand issues beyond simple access to HE but rather across the whole student 'lifecycle' (Atkins and Ebdon 2014), and there is an established interest in exploring issues of retention and success within particular disadvantaged groups (Reay et al. 2009). Of note are students from lower socio-economic groups or those with low income who are at higher risk of underachievement and attrition. OFFA have identified students from low-income backgrounds as both under-represented and disadvantaged within HE (OFFA 2016). Thus there is a need to better understand experiences of those specifically from households with income below the $£ 25,000$ per annum threshold. Additionally, the first year of undergraduate study has the highest rate of attrition, with non-continuation being most notable amongst non-traditional learners (OFFA 2016).

For example, the recent National Strategy on Access and Student Success set out the following aims:

a. Improve student retention, reducing the number of students who withdraw early from higher education;

b. Narrow the gap between the retention rates of the most advantaged and most disadvantaged;

c. Improve outcomes for different student groups by addressing the unexplained differentials in attainment.

(Atkins and Ebdon 2014, p.12) 
Part of the National Strategy also involved developing the knowledge, expertise and good practice that addresses non-continuation and disparities in attainment (Atkins and Ebdon 2014, p.66). However, the Strategy used language of deficit, concentrating on students' failures to complete and identifying narrow measures of attainment as its core concerns. The risk inherent in this approach is the replication of extant research which tells much about reasons for failure or underachievement, without directly illuminating how individuals overcome barriers and are supported to engage and succeed in the wider sense. Why is it that some students succeed despite multiple challenges? Why do some show great resilience and yet others may struggle or drop out? By applying a positive psychology model to the phenomenon of low income student success we can approach an understanding of academic resilience, including its relationship to success and achievement.

\section{Interpretative Phenomenological Analysis}

Since the individuals of most interest to WP researchers and practitioners are those who are often least heard; both researchers were inclined towards qualitative methodologies. Specific research questions looked at individual's experiences and sought to get close to the participant's inner world, and required a phenomenological approach. Furthermore, as the concepts of both aspiration and resilience stem from positive psychology, a rationale for choosing Interpretative Phenomenological Analysis (IPA) emerged.

IPA is a qualitative methodology introduced in 1996 by Jonathan Smith in the seminal paper 'Beyond the divide between cognition and discourse: Using interpretative phenomenological analysis in health psychology' as an alternative approach to quantitative and established qualitative methodologies used in psychology which prioritised the need for deep interpretation of participant accounts. In its most basic form, IPA is interested in examining how people make sense of major life experiences (Smith et al. 2009). The method has achieved widespread acceptance within certain fields of psychology such as health research, and has undergone further refinement by Smith, and others (Smith et al. 2009; (Eatough 2012).

Now, use of IPA has expanded into wider areas of psychology including educational research (Joseph and Southcott 2013; Thurston 2014; Rizwan and Williams 2015). Rizwan and Williams, for example used IPA to examine the experiences of young Pakistani girls in primary schools and 
found their identities were interwoven between experiences at school and their wider lives; including their home environment and community culture. Using IPA to research educational experiences is thus useful in exploring the interplay of many internal and external processes, situated in the context of individual's experiences.

This is particularly pertinent to understanding more about individual WP students' experiences across the lifecycle, where IPA as an approach is under-utilised. In one piece of WP research (Elmi-Glennan 2013), a group of six mature students were interviewed about their initial decisions to participate in $\mathrm{HE}$ and their on-going student experience using semistructured interviews with auto-driven photo elicitation (APE). The resulting analysis brought forth understanding of the ways in which relational social processes can act as motivations and barriers to learning. Studies of this design, whilst limited in their scope, demonstrate the advantages IPA can offer in exploring WP students' unseen experiences in greater depth.

By using IPA and by examining the lived world of a group of young people living in LPNs, and by understanding what meanings and perceptions they place on these experiences, the studies will help to understand their aspirations and how they are shaped as they progress through their school lives towards adulthood. Obtaining these insights will allow for a deeper account of individual experience to emerge (Willig 2013). It will also move away from more traditional studies that see aspiration as a measurable variable. This approach acknowledges a shift in the subject matter, with a movement away from a concern as to the nature of aspiration per se, to the actual participants and their experiences and understanding (Larkin et al. 2006).

Similarly, a critical review of resilience literature suggests that qualitative research could further enrich our understanding of student success and retention. Given the lack of in-depth research which considers the experience of resilience in under-represented groups in UK HE, the aim of the current study is to explore the phenomenon of academic resilience through the lived experience of low-income HE students. Listening to these experiences will provide rich, qualitative data to elucidate complex, situated processes. It will give volume to those 'quiet voices'; those young people who have overcome adversity, have gained entry to and are persisting at $\mathrm{HE}$ study. IPA has been chosen in order to gain insights into how particular individuals make sense of their own experience as students. The primary 
research question for this research is: 'How do university students from low income backgrounds experience academic resilience?'

\section{Theoretical underpinnings and rationale for use}

As both a philosophical framework and method of analysis, IPA is based on particular aspects of phenomenology and hermeneutics (see Figure 1). Its essential features are discussed here, along with the advantages and challenges they present for the two studies.

Figure 1: Essential features of IPA

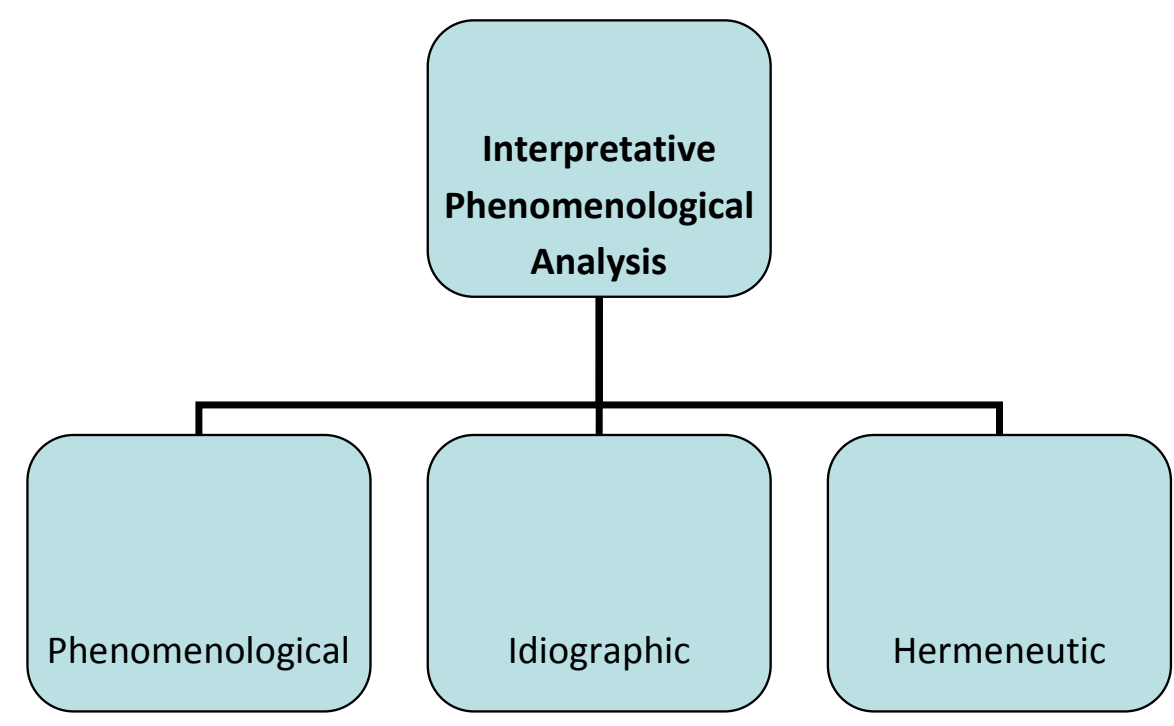

\section{Phenomenological}

IPA is phenomenological in that it is concerned with exploring and capturing the lived experience of a specified phenomenon (Smith 2004). It involves the detailed consideration of participants' 'lifeworlds'; the subjective and direct experience of one's physical surroundings and direct activities (Husserl 1970). This includes participants' experiences of a particular phenomenon, and how they have made sense of and given meaning to these experiences (Smith 2004). The goal of IPA research is not to produce an objective record of the event itself, but to explore a personal conception of a particular phenomenon, in line with the original thinking of Husserl (1970). 
As in the case of the student success study; a phenomenological methodology allows exploration of students' experiences of adversity and overcoming, focusing on description, relationships and interpretation rather than causality. This signifies a move away from traditional quantitative resilience research which seeks to identify and measure the impact of variables on quantifiable resilience levels (Ungar 2003), in a way that oversimplifies the experiences of students.

This poses considerable challenges for the IPA researcher; in developing broad objectives (what can a project using this methodology achieve, and what is it unable to achieve?), the data collection strategy and materials (will interview questions be overly directive? Will interviews or focus groups best capture the experience in question?) as well as in analysis and discussion (has interpretative analysis or descriptive analysis been achieved? Does the narrative stray into the territory of causal explanation?).

\section{Idiographic}

Much of the way in which young people's aspirations have been portrayed in WP policy can be said to be nomothetic, that is, generalised claims can be made at a group or population level about the aspirations of particular groups of young people. Likewise, with resilience research, risk and protective factors are typically quantified, with psychometric scales used to measure resilience within populations. IPA is however associated with an idiographic approach that whilst not deliberately avoiding making generalisations, seeks a different approach that locates them within the particular (Smith et al. 2009). Idiographic approaches are primarily concerned with the unique experiences of individuals, rather than establishing general rules. Whilst nomothetic studies can only make probabilistic claims about participants, within an idiographic study it is more possible to be able to make more specific claims about participants as analysis is embedded within individuals' accounts (Smith and Eatough 2012). In other words, an IPA study focuses on deeper level reflections of a few as opposed to the general insights of many (Charlick et al. 2015).

An idiographic approach also assumes a viewpoint where the individual is an active interpreter of their subjective world, rather than a passive recipient. This means in this viewpoint there is no objective reality or objective truth (Lyons and Coyle 2007). The advantage of this approach 
being that it enables the researcher to question what does the experience mean to this person and what sense does this person make of what is happening to them (Smith et al. 2009). An illustration of this from the student success study comes when comparing students sharing their experiences of difficult times during their first year:

Student One: "The constant challenge, the flow of work has kept me going. Some of my course mates are like, 'no I can't deal with it, I just need a break' and I think: 'No, I need it to help me keep going'."

Student Two: "I believe that university is an independent study...if I go into a job I'll never have one on one support, so I need to learn now how to survive on my own. So I'm here, educating myself to be independent."

In the first quote, the student identifies the pace of work as an external driver; it is challenging but it keeps him going. In contrast, the second quote comes from a student expressing her own values and beliefs about the purpose of the university experience; the transferable skill she believes she is developing serves as an internal motivator. Thus taking this idiographic approach allows such individual voices and experiences to be heard.

\section{Hermeneutic}

'Hermeneutic' within IPA can be defined as a method of interpretation. Whilst exploring the individual's personal experiences of their world is a goal of IPA, access to experiences of others is dependent also on the researcher's own conceptions. This principle makes IPA distinct from other forms of qualitative enquiry. 'Foreknowledge' is a term used in IPA which refers to the tools we each have that enable us to make sense of our own worlds, as well as the experience of others (Smith et al. 2009). Sensemaking necessitates interpretative activity; hence Heidegger's theory of hermeneutics in phenomenology is a touchstone of IPA (Heidegger 1927). To be means to be in the world; individual or dispositional processes are of diminished importance because individuals are inextricably related to others and the world. Thus, reflective processes in IPA take on a new aspect, one that is particularly temporal, social, and situated. Smith et al. (2009) describe this as the 'double hermeneutic' wherein the researcher must try to 
make sense of the experience that the participant has tried to share with them.

The major advantage of an interpretative methodology is it gives explicit recognition to the role of the researcher in the co-construction of phenomenon of concern, in a way that grounded theory, for example, does not. In terms of the student success project, coming to university means that the everyday flow of lived experience acquires a special significance for the individual. It is an important occasion and what Dilthey (1976) would describe as 'an experience' rather than just experience. The 'student experience' can be understood as a linked series of discrete experiences (application, enrolment, induction, attending classes, independent study, socialising, submitting assignments, using support services, participating in seminars and tutorials) which form a comprehensive unit of experience (Dilthey 1976). Indeed, particular events preceding the university experience may come to be viewed as part of the experience, despite being separated in time.

The advantage of using IPA here is that it allows the researcher to explore the phenomenon in a non-linear fashion. The major significance of the phenomenon means that the person who is subject to the experience are likely to have reflected on the events; considered how they think and feel about their time as an undergraduate student. Academic resilience as a phenomenon occurs in the space between a person, their environment and outcome, thus an interpretative approach is an advantage. Yet a key challenge here is how the IPA researcher can achieve a faithful interpretation of each participant's account, whilst also asking questions such as 'what assumptions underpin this account?' (Braun and Clarke 2013). These tensions will be explored further as we move on to discuss the approach to data analysis.

\section{Sampling in IPA research}

Whilst there is not an agreed sample size within IPA studies, the sample should be small enough to enable an idiographic analysis (Van Parys et al. 2014). In the access to HE study, this involved recruiting five participants from a Year 9 cohort who were all living in areas defined as a LPN. Similarly, in the student success study, a purposive sample of seven secondyear undergraduates from low-income backgrounds who offered a specific perspective on the phenomenon of resilience were recruited. 


\section{Data collection approaches}

Semi-structured individual interviews were used within both studies as the predominant approach to data collection. This is in line with the preferred means by which to gather date within an IPA study, due to the fact that interviews can be suited to in-depth personal discussion where participants are given space to think, speak and be heard (Smith et al. 2009). This allowed a greater personal construct of the participant to take place, given that each participant in an interview will define the situation in a particular way (Cohen and Manion 1991). Within the access to HE study, to explore the dynamic nature of aspiration, as well as the need to build rapport with participants, each participant partakes in four phases of data collection, starting with an initial focus group, followed by three individual semistructured interviews.

One of the key challenges of using interviews with an IPA study, however, is the fact that the process of an interview sees the use of 'talk', or language, as the way in which participants communicate their experiences. Willig (2013) suggests that this presupposes that the use of language provides participants with a suitable tool with which to share their experiences. Within the access to HE study, some participants, for example, found it hard to articulate their experiences or opinions within the first individual interview, responding with short answers, leaving long pauses or responding with 'don't know'. In an interview with Sophie ${ }^{3}$, for example, she discusses the conflict between being expected to think like an adult when she sees herself as barely a teenager. This suggests possible issues with the expectations on participants that they have thought about and are able to articulate responses to some of the questions asked of them.

"We're kind of just expected to always like think about what we're going to do when we're older ... rather than just like you're 14 years old, you're still a child, you don't have to think about all these crazy things. They just expect us to like act like adults even though we're barely teenagers."

It may be important therefore that researchers using IPA recognise that participants may need processes other than 'talk' to be able to describe their experiences. Smith (2004) suggests that when using IPA with children, the approach may need to be adapted to give the researcher a stronger role in guiding participants. To address this issue, in follow-up interviews more 
projective techniques, which can be described as 'a category of exercises that provoke imagination and creativity' (Mariampolski 2001, p.206) are being deployed. In the second set of interviews, a completion technique is used where participants are presented with a number of picture cards which all contained the start of a sentence. Participants select a card of their choice and complete the sentence. This then forms a basis for further discussion. This approach is particularly useful in allowing participants to take greater ownership of the discussions, whilst at the same time enabling aspects of their everyday lived experiences to emerge.

It should be acknowledged that if alternative methods are adopted, they must still enable the research questions to be answered, must still be sensitive to ethical issues and must be able to be undertaken within the necessary timescales (Fargas-Malet et al. 2010).

\section{Creating dynamic analysis: advantages and challenges}

There is no single, prescribed method for dealing with data in a study using IPA. The approach is better described as focusing on each participant's attempts to make sense of their experiences; a flexible process or cycle that is both iterative and inductive (Smith et al. 2009). Nonetheless, Smith and others offer a rough procedural guide to the novice IPA researcher. Here we briefly outline the guide, alongside its implementation for an excerpt of transcript from the student success study.

Firstly, the transcript material is typically read and re-read to develop a familiarity with the data which places the participant at the centre of analysis. In the case of the student success research, this has involved constructing an overview of the structure of the encounter and narrative. Whilst this initially presents as a kind of life story narrative, as a constructive process it allows the thoughts and feelings of the individual to begin to surface.

Initial notes or exploratory comments are made. Smith et al. (2009) advocate keeping an 'open mind'; a free textual analysis involving exploratory questioning should take place. The aim for both researchers in these projects at this stage has been to achieve a detailed and comprehensive set of notes on the data. This necessitates both a descriptive and phenomenological account, which makes explicit that which is important to 
the participant; what they mean or what things are like for them. A worked example can be seen in Table 1, which includes comments on the participant's use of language and context of their concerns. Descriptive notes highlight important objects and events, whilst figures of speech and emotional responses of researcher or interviewee are also noted. Specific linguistic features (pauses, pronouns, metaphors) and conceptual points (such as questions or repetitions) are also considered significant.

Table 1: Data analysis example from student success study

Part

A

\begin{tabular}{|l|l|l|}
\hline Emergent themes & Original Transcript & Exploratory comments \\
\hline $\begin{array}{l}\text { Sense of identity tied to } \\
\text { location }\end{array}$ & $\begin{array}{l}\text { Participant: Another bonus is that this uni is quite } \\
\text { far from where I'm from. So it's meant I get more } \\
\text { opportunities and it's just a better area to live in } \\
\text { for a while. }\end{array}$ & $\begin{array}{l}\text { Introduces self in relation to place } \\
\text { student }\end{array}$ \\
$\begin{array}{l}\text { Interviewer: So there's not so much opportunity } \\
\text { where you are from then? }\end{array}$ & $\begin{array}{l}\text { Significance of physical distance } \\
\text { from previous environment }\end{array}$ \\
\hline
\end{tabular}

Part 
B

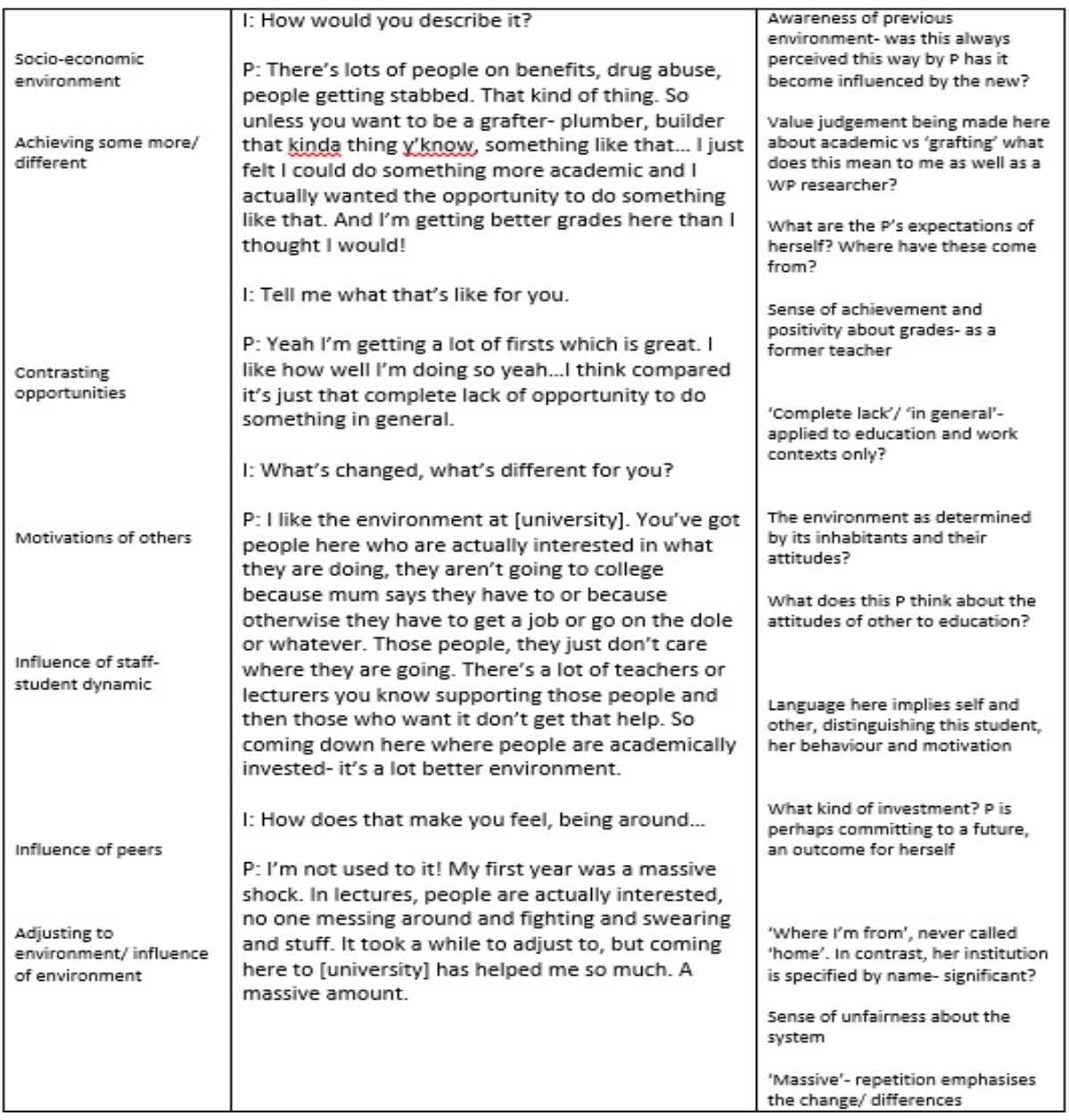

One challenge during this process is to consider and record how the analysis is informed by the researcher's own pre-understandings and their new understandings as the analysis move beyond superficial and descriptive. This is the essence of the hermeneutic, dynamic methodology. In the example of the student success study, reflections of this nature are expressed within the initial transcript notes and explored further with the researcher's reflexive journal to assist with later stages of interpretation.

One mark of quality in the data analysis component of an IPA enquiry is the extent to which participant's accounts are considered individually; as they happened within the context of the person's own specific circumstances, attitudes and previous experiences. Thus, the next stage of 
analysis undertaken by researchers is to transform notes into emerging themes through fragmenting and reorganising the material (see Table 1). Many potential initial themes may be rejected, combined or developed through the process of looking for relationships and connections between themes or 'clustering' (Pietkiewicz and Smith 2014). The outcome of this in-depth process is a final list comprised of a number of superordinate themes and subthemes from within each case, which are later used in crosscase analysis and described in narrative form.

In these later stages of analysis, there is a tension between the commitment of the researcher to a flexible, innovative approach and the process of writing up. How does one produce a creative, dynamic account? Additionally, the subjectivity that is inherent in the process is subject to scrutiny and should be systematic and rigorous in its application (Smith et al. 2009). Issues around quality and validity and their relevance to the two projects under consideration are explored elsewhere in this paper.

\section{Ethical challenges within IPA}

Whilst correct ethical practice is of paramount importance within any research study, the nature of phenomenological studies with the desire to enter the 'lifeworld' of participants places an increased emphasis on following correct and sensitive ethical procedures, particularly as the research may have certain effects on participants (such as discomfort and anxiety) (Van Manen 2007). At the heart of this is a duty of care as a researcher to ensure the physical and emotional safety of participants, particularly when, as in both studies, participants may share information that could be emotionally intense to reveal (Finlay and Evans 2009). Despite both studies having robust processes in place to try and anticipate any ethical issues, as Brinkmann and Kvale (2008) suggest, ethical issues may arise throughout the research process. During a session within the access to HE study, for example, one participant became extremely emotionally upset after sharing a personal story. A number of pre-planned procedures were then applied. This included an immediate ending of the session, withdrawal of the participant from the study, pastoral support for the young person and de-brief with the relevant staff member within the school.

This serves as a timely reminder to those who seek to gain a deeper understanding of the lives of young people from WP backgrounds. As 
researchers we should always be aware that many young people may live complex lives and have experienced deeply emotional events in their lives. At times this emotion may spill over into the research process. Despite this warning, researchers should not be put off in using more interpretative approaches to data collection, given the new perspectives it may be able to offer.

\section{Issues of quality and validity}

Qualitative research is subject to thorough consideration of quality, but requires different forms of measurement than quantitative methods. Thus, terminology within this paradigm moves away from traditional use of positivist criteria such as reliability, validity and generalisability (Finlay 2006). Nonetheless, carrying out an assessment of quality is essential for enquiries using IPA, as all interpretation contains implicit claims to authority (Denzin and Lincoln 1994). Smith and colleagues refer to Yardley's criteria for judging the essential qualities of all qualitative research: sensitivity to context, commitment and rigour, transparency and coherence, impact and importance. Some of these correspond to particular constructs from within quantitative research, as discussed below.

Sensitivity to context within the student success study is addressed through awareness of relevant literature in the fields of resilience research, WP research, policy and practice, as well as relevant texts on methodology. Whilst existing theory and empirical work can influence the interpretation of data, there needs to be evidence that any analysis is faithful and close to the data itself (Yardley 2000). This is explored through sharing examples of quotations and analysis with supervisors, and later in the study through discussion of results and reflexive summaries, which also consider the influence of the researcher on participant's accounts in terms of age, gender and perceived role in the research interaction. This will ensure a level of hermeneutic interpretation imperative for good quality IPA research.

Commitment and rigour are addressed by both researchers through intensive study of the methodological guidance on conducting an IPA study. Attempts to engage in-depth with the phenomena of aspiration and resilience are made through the idiographic nature of both studies, with their purposive, homogenous samples. A rigorous process of reading, analysis and interpretation occurs (as described earlier), in order to delve beyond 
descriptive accounts into detailed comparisons of individual cases which will elucidate each phenomenon.

The resulting narrative of the results presents the readership with a carefully constructed account of aspiration and the phenomenon of resilience in low-income students, but one that is grounded in details of their own words (Yardley 2000; 2008). The transparency of the method is evidenced in this study through an auditable trail of decisions. For example, the development of the interview guide is responsive to the input of the supervisory team, other WP researchers and the researchers' own reflections.

IPA cautions strongly against member checking and use of inter-judge reliability (Smith et al. 2009), which some may feel undermine the quality of results it can produce. However, efforts to pursue replicability or interjudge reliability would overlook the epistemological commitment to producing interpretative accounts of experience consistent with the aims of the methodology. This is because of the inherent subjectivity of IPA; no two individuals coding the same transcripts are likely to precisely replicate one another's analysis. However, sharing coding procedures, themes and participant quotes with the supervisory team provides the researcher with insight and motivation to ensure interpretation is logical and transparent to the reader.

In terms of impact and importance, Yardley (2000) argues that the decisive criteria by which any research should be judged is impact and utility (see Smith (2011) for specific criteria for judging an IPA paper). The findings of both studies will be disseminated in relevant journals and at relevant conferences. Both studies will offer a dual role in terms of impact. Firstly, both studies offer a novel, challenging way of looking at the phenomena of aspiration and resilience that aim to open up new theoretical ways of understanding the lives of WP students. This will provide original contributions to knowledge with WP research. Secondly, the studies will also offer methodological perspectives as to how IPA may be applied to future WP research.

\section{Reflexivity}

As IPA accepts that the analytic process is influenced by the interpretative framework of the researcher and its interaction with the accounts of participants (Arroll and Senior 2008), it follows that IPA studies 
recognise and acknowledge the role of researcher reflexivity. Indeed, unlike other forms of qualitative inquiry, IPA explicitly recognises data analysis as subjective and makes this transparent to the reader, avoiding attempts to 'bracket' or exclude this element.

Fook and Gardner (2007) see reflexivity as the ability to recognise that all aspects of ourselves and our contexts influence the way we research. To be reflexive we need to be aware of the many and varied ways in which we might create, or at least influence, the type of knowledge we use. This may involve exploring and developing areas such as power, control and inequalities, gender and age differences and involves critical self-reflection as well as an understanding of how the researchers background, assumptions, values, feelings and so on may impact on the research process (Finlay and Evans 2009).

Within a WP context, reflexivity can be said to be particularly pertinent given that WP research will often involve studying groups who may be vulnerable or under-represented and/or under-researched. By being reflexive the researcher can avoid the danger of misrepresenting the people being studied so as not to construct a subject or topic that reflects their own position as opposed to the actual participants (Langdridge 2007). Because of this, reflexivity should be seen as an ongoing process and can be revisited a number of times within the same study (Willig 2013). This involves, for example, adopting a reflexive attitude in developing the questions for the interviews, acknowledging the possible impact on the research of using semi-structured interviews, as well as being reflexive within the data analysis and write up stages. As Langdridge (2007) argues, to demonstrate that the researcher has taken reflexivity seriously an effort must be made to engage the reader in this process. In doing so, the researcher can also demonstrate how they have remained true to the theoretical underpinnings of IPA.

In the access to HE study the researchers' interpretative framework has been influenced, for example, by a number of years' experience in conducting WP research and their own transition to HE as a first generation student. By reflecting on previous experience the researcher has sought to minimise (as far as reasonably possible) some of the challenges and difficulties in conducting research within a school environment. This includes the interpretation by participants that the research constitutes 'school work' (Kellett and Ding 2004) and the need for the researcher to not 
be treated as a teacher (Hill 2006). All sessions have been conducted in a meeting room rather than a classroom to try and create a distance between participant's normal school setting and the research. Participants were also reminded that the sessions were not a lesson or a test and there were no right or wrong responses. Additionally, no school staff were present in any sessions. Previous experience suggests that the presence of staff can be restrictive and can potentially have an effect on the validity of the research (Greig et al. 2007). This is because of the possible effect on the adult-child power balance as well as the inability of the researcher to ask particular questions (especially around their school lives) for fear of embarrassing participants.

\section{Conclusion}

By offering the joint perspectives of two researchers using IPA in WP research, this article has discussed the possibilities and opportunities that IPA offers WP research. As with all phenomenological research, IPA is interested in exploring the world as directly and subjectively experienced by the individual, producing 'insider' meanings of what the lived experience feels like for the participants involved (Finlay 2014). With very little current use of IPA within WP research, this approach signifies a move away from more traditional approaches that may, for example, produce nomothetic claims of young people's aspirations or at times oversimplify the experiences of students.

By adopting an hermeneutic perspective, where there is more emphasis placed on interpretation over description (Langdridge 2007), and given the complexities of the phenomena of aspiration and academic resilience, may enable a deeper level of insight to emerge. Similarly, the idiographic nature of IPA, that sees participants as representing a perspective rather than a population (Smith et al. 2009) may allow more individualised perspectives of aspiration and academic resilience to emerge.

Applying IPA within a WP context is not without challenges. Willig (2013) provides a number of general concerns with IPA. Within the access to HE study, one of the key challenges has been the use of language and the assumption that this allows participants (particularly given their age) to convey their experiences in a manner that will allow for a phenomenological analysis. The article has provided information as to how the researcher has 
sought to overcome this. Likewise, in researching resilience, moving beyond a purely descriptive narrative of a student's first year experiences has been difficult. Discussing the sheer number of changes which happen in young people's lives during this period is time-consuming. Thus, transcript material is the product of lengthy encounters in which the researcher has probed key experiences and relationships in order to pursue and explore meaning.

Going forward, by examining the lived world of WP students and understanding what meanings and perceptions they place on experiences, should enable researchers to understand these experiences in new, subtle and different ways that can make a difference to the lived world of ourselves and others (Langdridge 2007). As Eatough and Smith (2008) suggest, IPA research can be appropriate in examining transformative experiences that bring about change to participants. This may be particularly pertinent to WP research, where young people may be considering, entering or indeed thriving in the world of HE, a world that may be unfamiliar to themselves and their families but a world that brings about transformative and fundamental changes to their lives.

Therefore, the findings of both studies should be of interest to others who are interested in the lived experiences of WP students and understanding how the individualised nature of these experiences may in turn break down some of the assumptions and stereotypes made about WP students. Understanding the stories of WP students can help HEIs to understand how they can become more accessible and supportive to non-traditional students, whilst taking into account individual differences, rather than adopting a 'one size fits all' approach.

We also hope that we will encourage fellow researchers to consider the use of phenomenological approaches as part of a mixed-methods approach to WP research.

\footnotetext{
${ }^{1}$ See https://www.offa.org.uk/access-agreements/

${ }^{2}$ A full definition is available at https://www.hesa.ac.uk/pis/defs.

${ }^{3}$ Name changed.
} 


\section{References}

Appadurai, A. (2004) 'The Capacity to Aspire: Culture and the Terms of Recognition'. In: Rao, V. and Walton, M., eds. Culture and Public Action. Stanford: Stanford University Press, 59-84.

Archer, L., DeWitt, J. and Wong, B. (2014) 'Spheres of Influence: what shapes young people's aspirations at Age 12/13 and what are the implications for education policy?' Journal of Education Policy, 29, 1: 58.

Arroll, M. A. and Senior, V. (2008). 'Individuals' experience of chronic fatigue syndrome/myalgic encephalomyelitis: an interpretative phenomenological analysis'. Psychology \& Health, 23, 4: 443.

Atkins, M. and Ebdon, L. (2014). National strategy for access and student success in higher education [Online]. Available at: http://dera.ioe.ac.uk/19859/1/bis-14-516national-strategy-for-access-and-student-success.pdf (Accessed September 2016).

Baker, W., Sammons, P., Siraj-Blatchford, I., Sylva, K., Melhuish, E. C. and Taggart, B. (2014) 'Aspirations, education and inequality in England: insights from the Effective Provision of Pre-school, Primary and Secondary Education Project'. Oxford Review of Education, 40, 5: 525.

Braun, V. and Clarke, V. (2013). Successful Qualitative Research: a practical guide for beginners. London: SAGE Publications Ltd.

Brinkmann, S. and Kvale, S. (2008). 'Ethics in Qualitative Psychological Research'. In: Willig, C. and Stainton Rogers, W. eds. The SAGE Handbook of Qualitative Research in Psychology. London: SAGE Publications Ltd.

Charlick, S. J., McKellar, L., Fielder, A. and Pincombe, J. (2015). 'Interpretative Phenomenological Analysis: Implementing Research to Influence Breastfeeding Education'. International Journal of Childbirth Education, 30, 2: 49.

Cohen, L. and Manion, L. (1991). Research methods in education. London: Routledge.

DBIS (2016). Success as a Knowledge Economy: Teaching Excellence, Social Mobility and Student Choice. London: Department for Business Innovation and Skills.

Denzin, N. and Lincoln, Y. (1994). Handbook of Qualitative Research. London: Sage Publications.

Dilthey, W. (1976). 'The development of hermeneutics'. In H. Rickman (Ed. \& Trans.), W. Dilthey: Selected writings: (Please add place of publication and publisher): 246.

Eatough, V. (2012). 'Introduction to Qualitative Methods'. In: Breakwell, G., Smith, J. and Wright, D. eds. Research Methods in Psychology. London: SAGE Publications Ltd: 321. 
Eatough, V. and Smith, J. (2008). Interpretative Phenomenological Analysis. In: Willig, C. and Stainton-Rogers, W. eds. The SAGE Handbook of Qualitative Research in Psychology. London: SAGE Publications Ltd, 179-194.

Elmi-Glennan, C. (2013). Influences of past and present relational social processes when entering higher education post 30 years : experiential accounts of foundation and year one students. (Doctor of Philosophy). Cardiff Metropolitan University.

Fargas-Malet, M., McSherry, D., Larkin, E. and Robinson, C. (2010). 'Research with Children: Methodological Issues and Innovative Techniques'. Journal of Early Childhood Research, 8, 2: 175.

Finlay, L. (2006). "Rigour', 'Ethical Integrity' or 'Artistry'? Reflexively Reviewing Criteria for Evaluating Qualitative Research'. British Journal of Occupational Therapy, 69, 7: 319.

Finlay, L. (2014). 'Engaging Phenomenological Analysis'. Qualitative Research in Psychology, 11, 2: 121.

Finlay, L. and Evans, K. (2009). Relational-centred research for psychotherapists: exploring meanings and experience. Oxford: Wiley-Blackwell.

Fook, J. and Gardner, F. (2007). Practicing Critical Reflection: A Resource Handbook. Maidenhead: Open University Press.

Greig, A., MacKay, T. and Taylor, J. (2007). Doing Research with Children. Los Angeles: Sage Publications Ltd.

Harris, M. (2010). What more can be done to widen access to highly selective universities? Bristol: The Office for Fair Access.

Harrison, N. and McCaig, C. (2015). 'An ecological fallacy in higher education policy: the use, overuse and misuse of 'low participation neighbourhoods'. Journal of Further and Higher Education, 39, 6: 793.

HEFCE, (2006). Widening Participation: A Review. Bristol: The Higher Education Funding Council for England.

Heidegger, M. (1927). Being and Time. Translated by John Macquarrie and Edward Robinson. San Francisco: Harper and Row.

Hill, M. (2006). 'Children's Voices on Ways of Having a Voice: Children's and Young People's Perspectives on Methods Used in Research and Consultation'. Childhood: A Global Journal of Child Research, 13, 1: 69.

Husserl, E. (1970). Logical Investigations. Translated by JN Findlay. New York: Humanities Press.

Joseph, D. and Southcott, J. (2013). 'So much more than just the music: Australian preservice music teacher education students' attitudes to artists-in-schools'. International Journal of Music Education, 31, 3: 243. 
Kellett, M. and Ding, S. (2004). 'Middle Childhood'. In: Fraser, S., Lewis, V., Ding, S., Kellett, M. and Robinson, C. eds. Doing Research with Children and Young People. London: SAGE Publications Ltd.

Kintrea, K., St Clair, R. and Houston, M. (2015). 'Shaped by place? Young people's aspirations in disadvantaged neighbourhoods'. Journal of Youth Studies, 18, 5: 666.

Langdridge, D. (2007). Phenomenological Psychology : Theory, Research and Method. Harlow: Prentice Hall.

Larkin, M., Watts, S. and Clifton, E. (2006). 'Giving voice and making sense in interpretative phenomenological analysis'. Qualitative Research in Psychology, 3, 2: 102 .

Lyons, E. and Coyle, A. (2007). Analysing Qualitative Data in Psychology. London: Sage Publications Ltd.

Mariampolski, H. (2001). Qualitative Market Research: a comprehensive guide. London: SAGE Publications Ltd.

OFFA, (2016). Frequently Asked Questions [online]. Available at: www.offa.org.uk/press/frequently-asked-questions/\#definitions [Accessed January 2016].

Pietkiewicz, I. and Smith, J. A. (2014). 'A practical guide to using Interpretative Phenomenological Analysis in qualitative research psychology'. Czasopismo Psychologiczne - Psychological Journal, 20, 1: 7.

Raco, M. (2009). 'From expectations to aspirations: State modernisation, urban policy, and the existential politics of welfare in the UK'. Political Geography, 28, 7, 436.

Reay, D., Crozier, G. and Clayton, J., 2009. "Strangers in Paradise'? Working-class Students in Elite Universities'. Sociology, 43, 6: 1103.

Rizwan, R. and Williams, A. (2015). "Only the wind hears you...' The experiences of Pakistani girls in a primary school: An Interpretative Phenomenological Analysis'. Educational \& Child Psychology, 32, 2: 36.

Sellar, S., Gale, T. and Parker, S. (2011). 'Appreciating aspirations in Australian higher education'. Cambridge Journal of Education, 41, 1: 37.

Smith, J. A. (1996). 'Beyond the divide between cognition and discourse: Using interpretative phenomenological analysis in health psychology'. Psychology and health, 11, 2: 261.

Smith, J. A. (2004). 'Reflecting on the development of interpretative phenomenological analysis and its contribution to qualitative research in psychology'. Qualitative Research in Psychology, 1, 1: 39. 
Smith, J. A. (2011). 'Evaluating the contribution of interpretative phenomenological analysis'. Health Psychology Review, 5, 1: 9.

Smith, J. A. and Eatough, V. (2012). 'Interpretative Phenomenological Analysis'. In: Breakwell, G., Smith, J. A. and Wright, D. eds. Research Methods in Psychology. London: SAGE Publications Ltd, 439.

Smith, J. A., Flowers, P. and Larkin, M. (2009). Interpretative Phenomenological Analysis: Theory, Method and Research. London: SAGE Publications Ltd.

Social Exclusion Task Force, (2008). Aspiration and attainment amongst young people in deprived communities. London: Cabinet Office.

Thurston, M. (2014). “They Think They Know What’s Best for Me”: An Interpretative Phenomenological Analysis of the Experience of Inclusion and Support in High School for Vision-impaired Students with Albinism'. International Journal of Disability, Development \& Education, 61, 2: 108.

Turok, I., Kintrea, K., St Clair, R. and Benjamin, A. (2009). Shaping educational attitudes and aspirations: the influence of parents, place and poverty: stage 1 report. York: Joseph Rowntree Foundation.

Ungar, M., (2003). 'Qualitative contributions to resilience research'. Qualitative Social Work, 2, 1: 85.

UUK, (2016). Working in Partnership: Enabling Social Mobility in Higher Education. London: Universities UK.

Van Manen, M. (2007). Researching Lived Experience: Human Science for an Action Sensitive Pedagogy. Ontario: The Althouse Press.

Van Parys, H., Smith, J. A. and Rober, P. (2014). 'Growing Up with a Mother with Depression: An Interpretative Phenomenological Analysis'. Qualitative Report, 19, 15: 1.

Willig, C. (2013). Introducing Qualitative Research in Psychology. Maidenhead, Berkshire: Open University Press.

Yardley, L. (2000). 'Dilemmas in Qualitative Health Research'. Psychology \& Health, 15, 2: 215.

Yardley, L. (2008). 'Demonstrating validity in qualitative psychology'. In J.A. Smith, ed. Qualitative psychology: A practical guide to methods $2^{\text {nd }}$ edition. London: SAGE Publications Ltd. 235. 
